\title{
INFLUENCE OF ORE GRADE AND MINERAL MEDIUM ON CHALCOPYRITE BIOLEACHING WITH MIXED MICROBIAL CONSORTIA
}

\author{
E. Benzal ${ }^{1}$, M. Solé ${ }^{1}$, C. Lao ${ }^{1}$, E. Morral ${ }^{1}$, X. Gamisans ${ }^{1}$, A.D. Dorado ${ }^{1 *}$ \\ ${ }^{1}$ Department of mining, industrial and ICT engineering, Universitat Politècnica de \\ Catalunya, Av. Bases de Manresa, 61-73, 08242 Manresa, Spain
}

\begin{abstract}
In the present work, key parameters in copper bioleaching from chalcopyrite have been investigated at long term operation. In detail, the type of mixed microbial consortium (origin and adaptation); the composition of two mineral media (the growth medium and
\end{abstract} the modified $9 \mathrm{~K}$ medium); its buffer capacity by the buffers $\mathrm{HCl} / \mathrm{KCl}$ and $\mathrm{Na}_{2} \mathrm{HPO}_{4} / \mathrm{KH}_{2} \mathrm{PO}_{4}$; and the influence of different ore grades in relation with the potential alkalinity associated have been investigated. For the first time, a mixed microbial consortium, obtained from a gas-phase biotrickling filter treating high loads of $\mathrm{H}_{2} \mathrm{~S}$, was employed revealing significant copper extraction by biological leaching. Results reveal that a single adaptation step of this biomass improved both kinetics and process efficiency, nearly doubling the amount of copper obtained compared with the nonadapted consortium. Nevertheless, the growth medium also influences the efficiency of the bioleaching process, enhancing copper extraction at higher sulphate concentration. The ore containing the metal is also a determining factor, obtaining same copper extraction for biotic and abiotic in one case, and enhancing up to 50 times from the abiotic in the other. Thus, this becomes a relevant limitation for the applicability of bioleaching for some ores, mainly due to the composition of the matrix.

Keywords: bioleaching, copper, metal recovery, microbial consortium, mineral medium 


\section{Introduction}

2 Chalcopyrite $\left(\mathrm{CuFeS}_{2}\right)$ is the most abundant copper ore; it is estimated that $80 \%$ of

3 worldwide copper reserves are formed by low-grade chalcopyrite deposits [1]. However,

4 this mineral source is especially recalcitrant and copper extraction by hydrometallurgical

5 processes is complex and expensive, especially from low-grade ores [2].

6 Bioleaching is an economically and environmentally friendly alternative method for

7 physicochemical extraction of metals. It consists of the release of metals from minerals

8 using microorganism activity. Bioleaching has been principally employed to extract

9 metals such as copper, nickel, cobalt and zinc, among others [3]. Usually, efforts have

10 been placed on low-grade ores because biological leaching is more profitable than

11 chemical leaching with these type of ores $[4,5]$.

12 In bioleaching, bacteria catalyses the oxidation of metal sulphides and two different mechanisms of bacterial action have been suggested: direct and indirect. The direct mechanism involves the attack and oxidation of the mineral surface by enzymatic reactions carried out by microorganisms. In this process, metal sulphides can be directly oxidized to soluble metals according to (Eq. 1) [6]:

$$
\mathrm{MS}+2 \mathrm{O}_{2} \rightarrow \mathrm{M}^{2+}+\mathrm{SO}_{4}^{2-}
$$

This mechanism is related to extracellular polymeric substances (EPS), which mediate the attachment of the cells to the ore surface [7]. The production of EPS depends on the strain and their culture conditions [8].

21 In the indirect mechanism, sulphide minerals are oxidized by ferric ions and the role of bacteria is to regenerate the oxidizing agent $\mathrm{Fe}(\mathrm{III})$. The different mineralogical characteristics cause two different dissolution pathways: via thiosulphate or polysulphide [9-11]. In particular, Zhao et al. [9] have described the mechanism of chalcopyrite mineral decomposition according to (Eqs. 2-3): 


$$
\mathrm{CuFeS}_{2}+4 \mathrm{Fe}^{3+} \rightarrow \mathrm{Cu}^{2+}+5 \mathrm{Fe}^{2+}+2 \mathrm{~S}
$$

Despite these two possible mechanisms, there is not a universally accepted theory about chalcopyrite bioleaching. For this reason, the mechanism of metal leaching is still under discussion, particularly the explanation of the direct mechanism [12-15]. Moreover, according to Zhao et al. [9], a non-oxidative dissolution of chalcopyrite occurs under acid conditions (Eq. 4):

$$
\mathrm{CuFeS}_{2}+4 \mathrm{H}^{+}+\mathrm{O}_{2} \rightarrow \mathrm{Fe}^{2+}+\mathrm{Cu}^{2+}+2 \mathrm{~S}^{0}+2 \mathrm{H}_{2} \mathrm{O}
$$

Microorganisms involved in bioleaching have an important role in the process. In this sense, it is well known that the use of pure cultures of Acidithiobacillus ferrooxidans or Acidithiobacillus thiooxidans in bioleaching results in high extraction yields of copper from minerals such as chalcopyrite [16]. However, mixed consortiums, containing these types of microorganisms can also be used for this purpose with several advantages such as the capacity to be adapted to the process in a short time and, thus, they are an economic alternative with greater potential for widespread use. [17-20]. In addition, it has been reported that the mixed consortia can be more efficient than pure culture since can be adapted easily to the process [21].

The most common mineral medium used in bioleaching, namely $9 \mathrm{~K}$, was described for the first time by Silverman and Lundgren [22]. Afterwards, some authors slightly modified its composition in respect of the amount of iron concentration and the addition of different salts. [18, 23-25]. These changes in the mineral medium composition could affected copper recovery, although there are no specific studies focusing on this bioleaching aspect.

pH also plays a critical role in bioleaching processes. Rohwerder et al. [12] concluded that the bioleaching process only could take place at $\mathrm{pH}$ around 2 in order to avoid a 
1 significant abiotic oxidation of ferrous iron. However, Wang et al. [16] affirmed that

2 below $\mathrm{pH} \mathrm{2,} \mathrm{a} \mathrm{considerable} \mathrm{inhibition} \mathrm{of} \mathrm{the} \mathrm{microorganisms} \mathrm{occurs.} \mathrm{For} \mathrm{this} \mathrm{reason,}$

3 many authors agree that a maintained value of $\mathrm{pH} 2$ along the whole bioleaching process

4 leads to better metal recoveries [26-28]. Nevertheless, the matrix of the ore used or the

5 mineral medium itself can change the alkalinity of the solution in which the bioleaching

6 takes place. In order to maintain acidic conditions, many authors add sulphuric acid to the

7 medium along the experiment [17, 29-32]. Another way to maintain a constant $\mathrm{pH}$ value

8 could be the use of appropriate buffer solutions in order to avoid the continuous acid

9 addition. However, to the best of our knowledge, the use of buffer solutions to maintain

10 acidic conditions in bioleaching processes is not described in the literature.

11 Accordingly, the main objective of the present work is to evaluate the effectiveness of copper bioleaching under different conditions using a mixed microbial consortium obtained from a gas-phase biotrickling filter operated at neutral $\mathrm{pH}$ and treating high loads of $\mathrm{H}_{2} \mathrm{~S}$. Both biotic and abiotic experiments were carried out in parallel under the same conditions in order to discriminate between chemical and biological processes, while the influence of two different mineral media on the process were also tested. In all cases, the influence of the buffer capacity of the mineral medium in contact with the mineral ore was analysed in terms of metal recovery.

\section{Materials and methods}

Mineral samples

22 The mineral used in this work was a chalcopyrite ore from the 'La Negra' mine (Querétaro, Mexico). Hereinafter, it will be called high-grade chalcopyrite. The mineral sample was analysed by atomic absorption spectrometry (AAS) after acid digestion. For this purpose, $0.15 \mathrm{~g}$ of ore (particle size below $63 \mu \mathrm{m}$ ) was digested with $10 \mathrm{~mL}$ of 


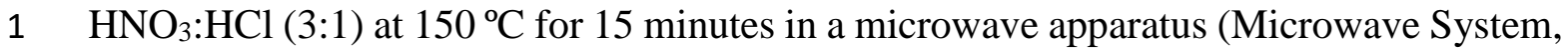

2 Millestone, Italy). The digestate was analysed with an atomic absorption spectrometer

3 (Solar S2, Thermo Scientific, United States). The whole procedure was repeated 5 times

4 to assess its repeatability. Copper concentration in mineral ore was $26.4 \%$ and the

5 coefficient of variation was lower than $1.5 \%$.

6 X-ray diffraction analysis was performed with a Panalytical X'Pert PRO MPD X-ray

7 diffractometer. Semi-quantitative mineral phase analysis of the sample determined by the

8 Rietveld method showed chalcopyrite at $68.0 \%$ (meaning a total copper concentration of

$923.5 \%$ ), calcite $12 \%$, sphalerite ferrous $5.0 \%$, pyrite $5.0 \%$, troilite $4.0 \%$, pyrrhotite $3.0 \%$

10 and quartz $3.0 \%$.

11 The particle size used in the bioleaching experiments was between 2 and $3 \mathrm{~mm}$, following the recommendations of Dorado et al. [19]. To obtain this size, the mineral was ground with a hammer mill (Serie 24, Humboldt Wedag Española SA, Spain) and sieved to the desired diameter range.

A second ore from the Misky deposit (Arquipa, Perú) was used to investigate the effect of the mineral range on the bioleaching process. The chemical analysis showed $0.62 \%$ of $\mathrm{Cu}$ (low-grade ore from now on). The mineral composition was quartz $98.0 \%$, chalcopyrite $1.2 \%$ (meaning a total copper concentration of $0.42 \%$ ) and malachite $0.5 \%$, with minor content of other sulphide minerals.

\section{Microorganisms}

A mixed microbial consortium obtained from a lab-scale gas-phase biotrickling filter operated at neutral $\mathrm{pH}$ and treating high loads of $\mathrm{H}_{2} \mathrm{~S}$ was used in this study. In particular, a sample of biomass was extracted from a lab-scale aerobic desulphurizing BTF, a diagram of which can be found in Fortuny et al. [33]. Three pieces of packing material with biofilm attached were collected and washed in $500 \mathrm{~mL}$ of mineral medium. 
1 Afterwards, the mineral medium with the suspended biomass was used to inoculate a

2 sterilized reactor $(2.8 \mathrm{~L})$, which was operated as a continuous stirred tank reactor. This

3 biomass was then cultured in an Erlenmeyer flask at $30^{\circ} \mathrm{C}$ and $200 \mathrm{rpm}$ before being used

4 as an inoculum in bioleaching experiments. This consortium was previously characterized

5 by Maestre et al. [34] by cloning and sequencing 16S rRNA fragments, identifying

6 Thiothrix spp, Sulfurimonas denitrificans, Halothiobacillus neapolitanus, Thiobacillus

7 denitrificans and Thiomonas intermedia as the most abundant species. In this work, the

8 consortium was used with and without previous adaptation. To adapt the culture, an initial

9 sample of the mixed microbial consortium was inoculated in a $500 \mathrm{~mL}$ Erlenmeyer flask

10 containing $100 \mathrm{~mL}$ of mineral medium and $10 \mathrm{~g}$ of chalcopyrite powder within 2-3 mm

11 particle diameter. This flask was kept at $30{ }^{\circ} \mathrm{C}$ and $120 \mathrm{rpm}$ using orbital shaking for 25

12 days.

Mineral media

Two different mineral media were tested in this study. Medium 1 was used in the labscale gas-phase biotrickling filter from which the consortium was obtained. The nonadjusted $\mathrm{pH}$ of these medium was 7 . Medium 2 was a modified 9K medium. Unlike 9K, the most widely employed literature-based medium for copper bioleaching studies, this medium did not contain iron (II). The $\mathrm{pH}$ was adjusted with sulphuric acid to $\mathrm{pH} 2$. The composition of two media are described in Table 1.

Regarding the buffering agent influence study, buffer solutions ( $\mathrm{HCl} / \mathrm{KCl}(0.10 \mathrm{M} / 0.09$ M) or $\mathrm{Na}_{2} \mathrm{HPO}_{4} / \mathrm{KH}_{2} \mathrm{PO}_{4}(0.065 \mathrm{M} / 0.025 \mathrm{M})$ were prepared before the salts of the mineral medium were added; $\mathrm{pH}$ was finally adjusted with $\mathrm{HCl}$ or $\mathrm{H}_{3} \mathrm{PO}_{4}$ to $\mathrm{pH} 2$.

\section{Bioleaching experiments}


1 Bioleaching experiments were performed in $500 \mathrm{~mL}$ Erlenmeyer flasks containing 100

$2 \mathrm{~mL}$ of mineral medium, $10 \mathrm{~g}$ of chalcopyrite ore (between 2 and $3 \mathrm{~mm}$ diameter) and 100

$3 \mathrm{~mL}$ of inoculum $\left(8.75 \cdot 10^{6}\right.$ cell $\left./ \mathrm{mL}\right)$. Abiotic experiments were carried out at the same

4 conditions without inoculum. The flasks were kept at $30{ }^{\circ} \mathrm{C}$ and shaken at $120 \mathrm{rpm}$. The

5 bioleaching experiments performed in this study are summarized in Table 2.

6

$7 \quad$ Analytical methods

8 Copper ions concentration in the Erlenmeyer was analyzed with an atomic absorption

9 spectrometer (Solar S2, Thermo Scientific, United States) after filtration of the 10 suspension through a $0.45 \mu \mathrm{m}$ membrane filter. For $\mathrm{pH}$ measurements, a Crison basic 25

$11 \mathrm{pH}$-meter was used. Samples were taken every 3 or 4 days, and the experiments were carried out between 15 and 80 days depending on the parameter studied. Concentration monitoring was performed during a total period of 170 days. The repeatability in the analysis was determined by replicates showing values between 0.1 and $5 \%$.

Influence of the mineral medium on copper recovery

The bioleaching process was studied using two different mineral media (medium 1 and medium 2) with the high-grade chalcopyrite sample. Values of copper recovery and $\mathrm{pH}$ along time are plotted in Fig. 1. Results reveal that copper release was detected after 30 days of experimentation in the two biotic samples, being negligible in samples without inoculum. However, there is a great difference between the amount of copper extracted using medium $2(200 \mathrm{mg} \mathrm{Cu} / \mathrm{L})$ and medium 1 (less than $25 \mathrm{mg} \mathrm{Cu} / \mathrm{L}$ ). This means that despite medium 1 being ideal for the growth of the consortium in the biofilter, where it was obtained for bioleaching, medium 2 was more suitable. In particular, the main 
1 difference between the composition of medium 1 and medium 2 was the amount of

2 sulphate ions $\left(0.078 \mathrm{~g} / \mathrm{L}\right.$ of $\mathrm{SO}_{4}{ }^{2-}$ and $6.055 \mathrm{~g} / \mathrm{L}$, respectively).

3 It is also worth noticing that, although medium 2 was adjusted to $\mathrm{pH} 2$ at the start of the

4 process, the $\mathrm{pH}$ increased up to 6 after 24 hours of contact with the ore in all biotic and

5 abiotic experiments. This means that those differences observed in copper extraction

6 between medium 1 and 2, could not be attributed to the initial $\mathrm{pH}$ of mineral media, but

7 to the medium composition itself. This alkalisation has also been described by Rodríguez

8 et al. [35], who attributed it to the protonic attack onto chalcopyrite (see Eq. 4). However,

9 this is not probably the cause of basification since it takes place very quickly during the

10 first five days, long before the copper release began, in both, biotic and abiotic samples.

$11 \mathrm{pH}$ alkalisation may be also attributed to the dissolution of basic salts originally contained in the ore matrix such as calcite. According to McGeouch et al. [36], calcite can be dissolved by the action of protons, resulting in alkalisation of the mineral medium (Eqs. 14 5-6).

$$
\mathrm{HCO}_{3}^{-}+\mathrm{H}^{+} \leftrightarrow \mathrm{H}_{2} \mathrm{CO}_{3} \rightarrow \mathrm{CO}_{2}+\mathrm{H}_{2} \mathrm{O}
$$

17 Conversely, it can also be observed that protons concentration slightly increased after 30 days in biotic samples. This acidification could be associated to the oxidation of sulphide by the sulphur-oxidizing microorganisms in mixed microbial consortium [9, 37]. Regarding abiotic samples, $\mathrm{pH}$ values kept quite constant, corroborating that acidification observed in biotic samples was due to microorganism activity. Although $\mathrm{pH}$ values decreased in both biotic samples, copper bioleaching was far higher in medium 2 than in medium 1, which confirms that this behaviour is related to the composition of the medium. As commented above, medium 2 contained 75 times more sulphate ion concentration than medium 1. According to Tuovinen and Kelly [38], sulphate is required 
1 by some microorganisms as a source of sulphur for biosynthesis, but also for several other

2 enzymatic functions. Thus, it seems that sulphate is a key parameter in microorganism

3 development and is probably the main reason for the differences in the recoveries of

4 copper obtained from the different media.

5 To ensure a proper operation over the entire bioleaching process, suspended biomass and

6 acidic conditions had to be maintained. However, originally, in the biotrickling filter from

7 which the biomass was obtained (see section 2.3.), the biomass was attached on a packed

8 support and under neutral $\mathrm{pH}$. These differences between biotrickling and bioleaching

9 conditions can result in a poor efficiency of bioleaching process. Therefore, a study with

10 a previously adapted biomass was carried out (section Microorganisms.). The evolution

11 of $\mathrm{pH}$ and copper concentration in the bioleaching media from the adapted and the nonadapted cultures are shown in Fig. 2.

As can be observed, the adapted culture improved both kinetics and efficiency of copper extraction with respect to the non-adapted one. Regarding kinetics, with the non-adapted biomass, copper bioleaching was observed after 25 days, whereas with the adapted biomass it began after 10 days (halving the start-up). On the other hand, when the adapted culture was used, the bioleaching effectiveness increased achieving a copper concentration of $450 \mathrm{mg} / \mathrm{L}$ compared with $250 \mathrm{mg} / \mathrm{L}$ obtained with the non-adapted one. Nevertheless, it is noteworthy that the kinetic of copper recovery was different. The nonadapted culture began to recover copper after 30 days with a leaching rate of 11.66 $\mathrm{mg} /(\mathrm{L} \cdot$ day $)$ whereas the adapted culture began before, but in this case, two velocities were observed. During the first 30 days, the copper leaching rate was $3.63 \mathrm{mg} /(\mathrm{L} \cdot$ day $)$, whereas from this time until 55 days the leaching rate was three times higher, achieving a rate of $12.13 \mathrm{mg} /(\mathrm{L} \cdot$ day $)$. Regarding $\mathrm{pH}$, this parameter increased at the beginning of the experiment in both, adapted and non-adapted microorganisms. However, during the first 
130 days, there is a greater $\mathrm{pH}$ decline in the case of the adapted microorganisms, which

2 indicates higher activity of the sulphur-oxidizing microorganism since the protons

3 concentration in the medium increases by the sulphur oxidation (Eq. 7) [39].

$$
\mathrm{S}+\mathrm{H}_{2} \mathrm{O}+1.5 \mathrm{O}_{2} \rightarrow \mathrm{H}_{2} \mathrm{SO}_{4}
$$

5 Furthermore, as can be seen in Fig. 2, after 60 days of experimentation, depletion on

6 copper concentration occurred in all biotic samples. It can also be observed that this

7 decrease in copper concentration coincided with an increase in $\mathrm{pH}$ values. This suggests

8 that reduction of copper concentration could be likely due to copper ion precipitation

9 through the formation of poor soluble species, resulting in copper(II) hydroxide (Eq. 8).

Nevertheless, this reaction occurred at $\mathrm{pH} 8$, so this cannot be the reason of copper

11 depletion.

$$
\mathrm{Cu}^{2+}+2 \mathrm{OH}^{-} \rightarrow \mathrm{Cu}(\mathrm{OH})_{2}
$$

This behaviour has not been described before in chalcopyrite bioleaching studies found in the literature. Many bioleaching studies in batch conditions have been performed during less than 60 days [40-45] and, to the best of our knowledge, studies that experimented beyond this time span are scarce in the literature. Long-term chalcopyrite bioleaching studies $[16,18,46-48]$ have not described a reduction in copper concentration. However, the conditions under which the experiments were performed in these studies differ from those of the present (e.g. the $\mathrm{pH}$ was maintained at very acidic values along all the duration of the experiments). When the decrease of copper concentration was detected, a concomitant formation of an orange-brown precipitate was observed. It is thought that the precipitate could be jarosite. It is well known that in the chalcopyrite bioleaching process, the formation of iron precipitates such as jarosite is $\mathrm{pH}$ dependent, being the formation of jarosite favored at higher $\mathrm{pH}$ [49]. In this sense, the $\mathrm{pH}$ 
1 jarosite could be formed at these conditions and, according to Zhou et al. [27], jarosite

2 formation could lock some of the extracted copper (Eq. 9).

3

5

6

7

$$
3 \mathrm{Fe}^{3+}+\mathrm{M}^{+}+2 \mathrm{HSO}_{4}^{-}+6 \mathrm{H}_{2} \mathrm{O} \rightarrow \mathrm{MFe}_{3}\left(\mathrm{SO}_{4}\right)(\mathrm{OH})_{6}+8 \mathrm{H}^{+}
$$

\section{Buffering the bioleaching mineral media}

Most of the microorganisms used in metals recovery by bioleaching grow at very acidic $\mathrm{pH}$ (below 2.5) [12]. However, the optimum $\mathrm{pH}$ value for bioleaching processes depends on the type of microorganisms [50]. Furthermore, the gangue components of the ore can also affect the medium $\mathrm{pH}$ and thus, have some influence on the efficiency in the bioleaching processes. In the present study, initial $\mathrm{pH}$ was adjusted to $\mathrm{pH} 2$ due to results obtained in a previous study that worked with the same consortium [19]. Nevertheless, this value increased quickly during the first stage of the bioleaching experiments (Fig. 2). It is associated with the consumption of protons due to the solubilisation of the ore components. This alkalisation has been observed in numerous studies and generally, the maintenance of $\mathrm{pH}$ along the bioleaching process is accomplished by periodic addition of sulphuric acid [18, 44, 48, 51, 52].

In order to avoid the constant addition of acid, which raises the cost, makes the recovery process less sustainable, and is not being always technically possible, two different buffer solutions $\mathrm{HCl} / \mathrm{KCl}$ (chloride buffer) and $\mathrm{Na}_{2} \mathrm{HPO}_{4} / \mathrm{H}_{3} \mathrm{PO}_{4}$ (phosphate buffer) were tested during chemical leaching of low-grade chalcopyrite. Both buffer solutions are usually used in biological and chemical processes to keep $\mathrm{pH}$ at values of 2. Evolution of $\mathrm{pH}$ over time in buffered media is shown in Fig. 3. Results reveal that while the phosphate buffer kept well the $\mathrm{pH}$ around 2, chloride buffer was not able to maintain the $\mathrm{pH}$ of the media at $\mathrm{pH} 2$ when the ore was present in the bioleaching media. Although the phosphate buffer maintained the $\mathrm{pH}$, the formation of a precipitate was observed which could be due to the reaction between phosphate anions and metallic cations present in the mineral medium, 
1 such as iron and calcium. This can seriously affect the bioleaching process because of the

2 decrease in concentration of essentials ions which are necessary for the biological process

3 performance.

4

\section{$5 \quad$ Effect of the ore on bioleaching process}

6 Bioleaching processes can be applied to copper ores of different grades and composition

$7 \quad[6,28]$. This fact might influence the process because some components contained in the

8 ore would be able to react with the mineral medium. For this reason, in the present study

9 two different copper ores, which have different percentage of copper, were investigated.

10 Experiments were performed with medium 2, which presented higher recovery as

11 described in section Mineral media.

12 Copper concentration and $\mathrm{pH}$ evolution over time are shown in Fig. 4. Results reveal that copper extraction occurred from both ores. As can be seen, after 18 days, the amount of copper extracted was higher from high-grade chalcopyrite $(47 \mathrm{mg} / \mathrm{L})$ than from low-grade chalcopyrite $(10 \mathrm{mg} / \mathrm{L})$. Moreover, the recovery of copper in the biotic experiment with the high-grade chalcopyrite $(47 \mathrm{mg} / \mathrm{L})$ is nearly 50 times higher than in the abiotic control $(1 \mathrm{mg} / \mathrm{L})$. On the contrary, it is noteworthy that the amount of copper extracted from lowgrade chalcopyrite was the same in biotic and abiotic samples. This suggests that copper obtained from the low-grade ore was leached chemically without the intervention of microorganisms. The inactivity of the biomass in this case could be caused by some components present in the ore matrix capable of inhibiting the metabolism of the microorganisms. Thus, it confirms that the ore composition is important and not all copper ore minerals are suitable for bioleaching. On the contrary, there was a noticeable difference between biotic and abiotic samples from the high-grade chalcopyrite. The copper obtained from biotic sample was over 40 times greater than the copper obtained from the abiotic experiment. 
1 In terms of copper extraction, the amount of copper obtained with the high-grade

2 chalcopyrite represented an extraction of $2 \%$ in weight. These results are in agreement

3 with those obtained by Dong et al. [53], who obtained between 2-10\% of copper from

4 two samples of chalcopyrite with similar composition of the ore used in the present work

$5 \quad(24 \% \mathrm{Cu}, 27 \% \mathrm{Fe}$ and $30 \% \mathrm{~S})$ during the same experimental time.

6 Copper concentration obtained with the high-grade chalcopyrite was 5 times greater than

7 that obtained with the low-grade chalcopyrite. However, in terms of copper recovery,

$814 \%$ of copper from the low-grade ore was obtained whereas only $2 \%$ was obtained from

9 the high-grade sample. These results might be related to the high quartz content in the

10 low-grade chalcopyrite (98\%). Dong et al. [53] demonstrated that copper bioleaching

11 from chalcopyrite was improved by the addition of quartz in the bioleaching medium.

12 According to these authors, the presence of fine particles of quartz could reduce the

13 formation of a passivating jarosite layer on the ore that negatively affects copper

14 extraction.

15 It is also noteworthy to point out that $\mathrm{pH}$ values follow a similar behaviour in all cases.

16 After the first 24 hours, the $\mathrm{pH}$ increased substantially and then, the values were almost

17 constant until the end of the experiment. The initial alkalisation was more pronounced in the high-grade chalcopyrite sample probably due to the matrix composition of the ore, since one component of the matrix is the calcite, which could produce alkalization as was remarked in section 3.1 .

\section{Conclusions}

This study demonstrated that a microbial consortium obtained from a lab-scale gas-phase biotrickling filter (BTF) was efficient for copper bioleaching from chalcopyrite. The amount of copper obtained was doubled with a previous adaptation of the culture. Efficiency of the process was positively influenced by the content of sulphate in 
1 bioleaching medium. After 60 days of operation, depletion of copper concentration

2 occurred simultaneously with an increase in $\mathrm{pH}$, both in biotic and abiotic tests, which

3 was related to copper ions precipitation through the formation of low soluble species that

4 could lock some of the extracted copper. The use of buffer solutions $(\mathrm{HCl} / \mathrm{KCl}$ and

$\left.5 \mathrm{Na}_{2} \mathrm{HPO}_{4} / \mathrm{KH}_{2} \mathrm{PO}_{4}\right)$ to maintain the $\mathrm{pH}$ at low values did not improve the process,

6 precipitating species needed for bioleaching process. The type of ore also affects the

7 efficiency; in particular, the copper extracted in biotic test for high-grade chalcopyrite

8 was nearly 50 times greater than in abiotic, whereas no differences were detected in low-

9 grade chalcopyrite. Matrix composition of the ore was responsible of inhibiting the

10 activity of the microorganisms being a relevant limitation for the applicability of

11 bioleaching for some ores with copper.

Acknowledgments

Eva Benzal gratefully acknowledges a FPU-2014 predoctoral scholarship from Ministerio de Educación, Cultura y Deporte (Spain) and co-financed by FEDER funds. We acknowledge the help obtained from Dra. Pura Alfonso of Universitat Politècnica de Catalunya in the supply of mineral samples and their characterization.

\section{References}

1. Morin, D. (2008). Biotechnology for Metal bearing materials in Europe Nanotechnologies and nanosciences, knowledge-based multifunctional materials, and new production processes and devices, FP6 Integr. France

2. Tanne, C.K., Schippers, A. (2019). Electrochemical Applications in Metal Bioleaching. Adv. Biochem. Eng. Biotechnol., 167, 327-359.

3. Martinez, P., Vera, M., Bobadilla-Fazzini, R.A. (2015). Omics on bioleaching: current and future impacts. Appl. Microbiol. Biotechnol., 99, 8337-8350. 
1 4. Song, J., Franzmann, P.D., Lin, J., Lin, J., Kaksonen, A.H. (2011). Respirometry studies of bioleaching of low-grade chalcopyrite ore using six acidophilic strains. Miner. Eng., 24, 1139-1145.

5. Saitoh, N., Nomura, T., Konishi, Y. (2017). Bioleaching of Low-Grade Chalcopyrite Ore by the Thermophilic Archaean Acidianus brierleyi. Solid State Phenom., 262, 237-241.

6. Dong, Y., Lin, H., Xu, X., Zhou, S. (2013). Bioleaching of different copper sulfides by Acidithiobacillus ferrooxidans and its adsorption on minerals. Hydrometallurgy, 140, 42-47.

7. Vera, M., Schippers, A., Sand, W. (2013). Progress in bioleaching: fundamentals and mechanisms of bacterial metal sulfide oxidation--part A. Appl. Microbiol. Biotechnol., 97, 7529-7541.

8. He, Z.G., Yang, Y.P., Zhou, S., Hu, Y.H., Zhong, H. (2014). Effect of pyrite, elemental sulfur and ferrous ions on EPS production by metal sulfide bioleaching microbes. Trans. Nonferrous Met. Soc. China, 24, 1171-1178.

9. Zhao, H., Zhang, Y., Zhang, X., Qian, L., Sun, M., Yang, Y., Zhang, Y., Wang, J., Kim, H., Qiu, G. (2019). The dissolution and passivation mechanism of chalcopyrite in bioleaching: An overview. Miner. Eng., 136, 140-154.

10. Mahmoud, A., Cézac, P., Hoadley, A.F.A., Contamine, F., D'Hugues, P. (2017). A review of sulfide minerals microbially assisted leaching in stirred tank reactors. Int. Biodeterior. Biodegrad. 119, 118-146.

11. Pattanaik, A., Sukla, L.B., Pradhan, D., Krishna Samal, D.P. (2020). Microbial mechanism of metal sulfide dissolution. Mater. Today Proc., 1-6.

12. Rohwerder, T., Gehrke, T., Kinzler, K., Sand, W. (2003). Bioleaching review part A: progress in bioleaching: fundamentals and mechanisms of bacterial metal 
sulfide oxidation. Appl. Microbiol. Biotechnol., 63, 239-48.

13. Ehrlich, H.L. (2002), How microbes mobilize metals in ores: A review of current understandings and proposals for further research. Miner. Metall. Process., 19, $220-224$.

14. Sand, W., Gerke, T., Hallmann, R., Schippers, A. (1995). Sulfur chemistry, biofilm, and the (in)direct attack mechanism - a critical evaluation of bacterial leaching. Appl. Microbiol. Biotechnol., 43, 961-966.

15. Liu, H., Lu, X., Zhang, L., Xiang, W., Zhu, X., Li, J., Wang, X., Lu, J., Wang, R. (2018). Collaborative effects of Acidithiobacillus ferrooxidans and ferrous ions on the oxidation of chalcopyrite. Chem. Geol., 493, 109-120.

16. Wang, J., Zhu, S., Zhang, Y.S., Zhano, H.B., Hu, M.H., Yang, C.R., Qin, W.Q., Qiu, G.Z. (2014). Bioleaching of low-grade copper sulfide ores by Acidithiobacillus ferrooxidans and Acidithiobacillus thiooxidans. J. Cent. South Univ., 21, 728-734.

17. Qin, W., Yang, C., Lai, S., Wang, J., Liu, K., Zhang, B. (2013). Bioleaching of chalcopyrite by moderately thermophilic microorganisms. Bioresour. Technol. 129, 200-208.

18. Zhang, Y.S., Qin, W.Q., Wang, J., Zhen, S.J., Yang, C.R., Zhang, J.W., Nai, S.S., Qiu, G.Z. (2008). Bioleaching of chalcopyrite by pure and mixed culture. Trans. Nonferrous Met. Soc. China, 18, 1491-1496.

19. Dorado, A.D., Solé, M., Lao, C., Alfonso, P., Gamisans, X. (2012). Effect of pH and Fe(III) ions on chalcopyrite bioleaching by an adapted consortium from biogas sweetening. Miner. Eng., 39, 36-38.

20. Ma, L., Wang, X., Liu, X., Wang, S., Wang, H. (2018). Intensified bioleaching of chalcopyrite by communities with enriched ferrous or sulfur oxidizers. Bioresour. 
Technol., 268, 415-423.

21. Baniasadi, M., Vakilchap, F., Bahaloo-Horeh, N., Mousavi, S.M., Farnaud, S. (2019). Advances in bioleaching as a sustainable method for metal recovery from e-waste: A review. J. Ind. Eng. Chem. https://doi.org/10.1016/j.jiec.2019.03.047

22. Silverman, M.P., Lundgren, D.G. (1959). Studies on the chemoautotrophic iron bacterium Ferrobacillus ferrooxidans. J. Bacteriol., 77(5), 642-664.

23. Fu, B., Zhou, H., Zhang, R., Qiu, G. (2008). Bioleaching of chalcopyrite by pure and mixed cultures of Acidithiobacillus spp. and Leptospirillum ferriphilum. Int. Biodeterior. Biodegradation, 62, 109-115.

24. Córdoba, E.M., Muñoz, J.A., Blázquez, M.L., González, F., Ballester, A. (2008). Leaching of chalcopyrite with ferric ion. Part IV: The role of redox potential in the presence of mesophilic and thermophilic bacteria. Hydrometallurgy, 93, 106-115.

25. Fu, K., Lin, H., Cheng, H., Mo, X.L., Dong, Y.B. (2013). Bioleaching of djurleite using Acidithiobacillus ferrooxidans. Miner. Eng., 40, 38-41.

26. Yin, S., Wu, A., Qiu, G. (2008). Bioleaching of low-grade copper sulphides. Trans. Nonferrous Met. Soc. China, 18, 707-713.

27. Zhou, H.B., Zeng, W.M., Yang, Z.F., Xie, Y.J., Qiu, G.Z. (2009). Bioleaching of chalcopyrite concentrate by a moderately thermophilic culture in a stirred tank reactor. Bioresour. Technol., 100, 515-520.

28. Dong, Y.B., Lin, H., Fu, K.B., Xu, X.F., Zhou, S.S. (2013). Bioleaching of two different types of chalcopyrite by Acidithiobacillus ferrooxidans. Int. J. Miner. Metall. Mater., 20, 119-124

29. Khoshkhoo, M., Dopson, M., Shchukarev, A., Sandström, Å. (2014). Chalcopyrite leaching and bioleaching: An X-ray photoelectron spectroscopic (XPS) investigation on the nature of hindered dissolution. Hydrometallurgy, 149, 220- 
227.

30. Huang, T., Wei, X., Zhang, S. (2019). Bioleaching of copper sulfide minerals assisted by microbial fuel cells. Bioresour. Technol., 288, 121561.

31. Yaghobi Moghaddam, M., Ranjbar, M., Manafi, Z., Schaffie, M., Jahani, M. (2012). Modeling and optimizing bacterial leaching process parameters to increase copper extraction from a low-grade ore. Miner. Eng., 32, 5-7.

32. Zhao, C.X., Yang, B.J., Wang, X.X., Zhao, H.B., Gan, M., Qiu, G.Z., Wang, J. (2020). Catalytic effect of visible light and $\mathrm{Cd} 2+$ on chalcopyrite bioleaching. Trans. Nonferrous Met. Soc. China (English Ed), 30, 1078-1090.

33. Fortuny, M., Guisasola, A., Casas, C., Gamisans, X., Lafuente, J., Gabriel, D. (2010). Oxidation of biologically produced elemental sulfur under neutrophilic conditions. J. Chem. Technol. Biotechnol., 85, 378-386.

34. Maestre, J.P., Rovira, R., Alvarez-Hornos, F.J., Fortuny, M., Lafuente, J., Gamisans, X., Gabriel, D. (2010). Bacterial community analysis of a gas-phase biotrickling filter for biogas mimics desulfurization through the rRNA approach. Chemosphere, 80, 872-880.

35. Rodríguez, Y., Ballester, A., Blázquez, M.L., González, F., Muñoz, J.A. (2003). New information on the chalcopyrite bioleaching mechanism at low and high temperature. Hydrometallurgy, 71, 47-56.

36. McGeouch, C.A., Peruffo, M., Edwards, M.A., Bindley, L.A., Lazenby, R.A., Mbogoro, M.M., McKelvey, K., Unwin, P.R. (2012). Quantitative localized proton-promoted dissolution kinetics of calcite using scanning electrochemical microscopy (SECM). J. Phys. Chem. C., 116, 14892-14899.

37. Sand, W., Gehrke, T., Jozsa, P.G., Schippers, A. (2001). (Bio)chemistry of bacterial leaching - direct vs. indirect bioleaching. Hydrometallurgy, 59, 159-175. 
138. Tuovinen, O.H., Kelly, D.P. (1973). Studies on the Growth of Thiobacillus ferrooxidans. Arch. Mikrobiol., 88, 285-298.

39. Pathak, A., Srichandan, H., Kim, D.J. (2019). Column bioleaching of metals from refinery spent catalyst by Acidithiobacillus thiooxidans: Effect of operational modifications on metal extraction, metal precipitation, and bacterial attachment. J. Environ. Manage., 242, 372-383.

40. Vilcáez, J., Yamada, R., Inoue, C. (2009). Effect of pH reduction and ferric ion addition on the leaching of chalcopyrite at thermophilic temperatures. Hydrometallurgy, 96, 62-71.

41. Klink, C., Eisen, S., Daus, B., Heim, J., Schlömann, M., Schopf, S. (2016). Investigation of Acidithiobacillus ferrooxidans in pure and mixed-species culture for bioleaching of Theisen sludge from former copper smelting. J. Appl. Microbiol., 120, 1520-1530.

42. Peng, T., Zhou, D., Liu, X., Yu, R.L., Jiang, T., Gu, G.H., Chen, M., Qiu, G.Z., Zeng, W.M. (2016). Enrichment of ferric iron on mineral surface during bioleaching of chalcopyrite. Trans. Nonferrous Met. Soc. China, 26, 544-550.

43. Shabani, M.A., Irannajad, M., Meshkini, M., Azadmehr, A.R. (2019). Investigations on Bioleaching of Copper and Zinc Oxide Ores. Trans. Indian Inst. Met., 72, 609-611.

44. Nie, Z.Y., Zhang, W.W., Liu, H.C., Zhu, H.R., Zhao, C.H., Zhang, D.R., Zhu, W., Ma, C.Y., Xia, J.J. (2019). Bioleaching of chalcopyrite with different crystal phases by Acidianus manzaensis. Trans. Nonferrous Met. Soc. China (English Ed), $29,617-624$.

45. Konadu, K.T., Sakai, R., Mendoza, D.M., Chuicham, C., Miki, H., Sasaki, K. (2020). Effect of carbonaceous matter on bioleaching of $\mathrm{Cu}$ from chalcopyrite ore. 
Hydrometallurgy, 195, 105363.

46. Thurston, R.S., Mandernack, K.W., Shanks, W.C. (2010). Laboratory chalcopyrite oxidation by Acidithiobacillus ferrooxidans: Oxygen and sulfur isotope fractionation. Chem. Geol., 269, 252-261.

47. Zhao, X., Wang, R., Lu, X., Lu, J.J., Li, C.X., Li, J. (2013). Bioleaching of chalcopyrite by Acidithiobacillus ferrooxidans. Miner. Eng., 53, 184-192.

48. Cancho, L., Blázquez, M.L., Ballester, A., González, F., Muñoz, J.A. (2007). Bioleaching of a chalcopyrite concentrate with moderate thermophilic microorganisms in a continuous reactor system. Hydrometallurgy, 87, 100-111.

49. Daoud, J., Karamanev, D. (2006). Formation of jarosite during Fe2+ oxidation by Acidithiobacillus ferrooxidans. Miner. Eng., 19, 960-967.

50. Plumb, J.J., Muddle, R., Franzmann, P.D. (2008). Effect of pH on rates of iron and sulfur oxidation by bioleaching organisms. Miner. Eng., 21, 76-82.

51. Zhao, H., Wang, J., Yang, C., Hu, M., Gan, X., Tao, L., Qin, W., Qiu, G. (2015). Effect of redox potential on bioleaching of chalcopyrite by moderately thermophilic bacteria: An emphasis on solution compositions. Hydrometallurgy, $151,141-150$.

52. Akcil, A., Ciftci, H., Deveci, H. (2007). Role and contribution of pure and mixed cultures of mesophiles in bioleaching of a pyritic chalcopyrite concentrate. Miner. Eng., 20, 310-318.

53. Dong, Y., Lin, H., Zhou, S., Xu, X., Zhang, Y. (2013). Effects of quartz addition on chalcopyrite bioleaching in shaking flasks. Miner. Eng., 46-47, 177-179. 